\title{
Erratum to: Ion reduction in metallic nanoparticles nucleation and growth on cellulose films: Does substrate play a role?
}

\author{
Ana Patrícia Carapeto - Ana Maria Ferraria • \\ Sami Boufi • Manuel Rei Vilar • \\ Ana Maria Botelho do Rego
}

Published online: 3 January 2015

(C) Springer Science+Business Media Dordrecht 2015

\section{Erratum to: Cellulose DOI 10.1007/s10570-014-0468-z}

In the original publication of the article, the following errors occurred inadvertently.

Under the section "NPs formation mechanism,"

Equations (3) and (5) should be written as follows:

$$
\begin{gathered}
2 \mathrm{CHOH}+\mathrm{CH}_{2} \mathrm{OH}+\mathrm{H}_{2} \mathrm{O} \rightleftarrows 2 \mathrm{C}=\mathrm{O} \\
+\mathrm{COOH}+8 \mathrm{H}^{+}+8 \mathrm{e}^{-}
\end{gathered}
$$

$$
\begin{aligned}
& 8\left[\mathrm{AuCl}_{4}\right]^{-}(\text {aq. })+6 \mathrm{CHOH}+3 \mathrm{CH}_{2} \mathrm{OH} \\
& \quad+\mathrm{H}_{2} \mathrm{O} \rightleftarrows 8 \mathrm{Au}(s)+32 \mathrm{Cl}^{-}(\text {aq. })+6 \mathrm{C}=\mathrm{O} \\
& \quad+3 \mathrm{COOH}+4 \mathrm{H}^{+}
\end{aligned}
$$

The computed number of reduced gold atoms for each nanoparticle is equal to 757,111 . The number 1 , hanging on the right apart from the expression, must be ignored.

In Fig. 7 caption and in the corresponding text below, the XPS region Carbon 1s should be written following the conventional notation form $\mathrm{C} 1 \mathrm{~s}$.

The online version of the original article can be found under doi:10.1007/s10570-014-0468-z.

A. P. Carapeto - A. M. Ferraria (凶) - A. M. B. do Rego Centro de Química-Física Molecular and IN, Instituto Superior Técnico, Universidade de Lisboa, Av. Rovisco Pais, 1049-001 Lisbon, Portugal e-mail: ana.ferraria@tecnico.ulisboa.pt

S. Boufi LMSE, Faculty of Science, University of Sfax, Route Soukra, BP 1171-3000 Sfax, Tunisia

M. R. Vilar ITODYS, UMR7086 CNRS, Université Paris Diderot, Sorbonne Paris Cité, 15, Rue Jean Antoine de Baiff, 75205 Paris Cedex 13, France 